\title{
Acting with Restraint
}

Robert L. Kane, MD

University of Minnesota School of Public Health, Minneapolis, MN, USA.

J Gen Intern Med 32(1):9-10

DOI: $10.1007 / \mathrm{s} 11606-016-3861-5$

(c) Society of General Internal Medicine 2016

A bout 50 years ago, Avedis Donabedian proposed a taxonomy for quality of care based on the presumed interrelationship of three factors - structure, process, and outcomes. ${ }^{1,2}$ Since then, researchers have tried to establish this relationship with limited success. ${ }^{3}$ Belief in the relationship of structure, process, and outcomes forms the foundation for evidence-based practice. Unfortunately, the strength of evidence is weak. ${ }^{4}$ The paper by Staggs and colleagues represents another effort to link structure (nurse staffing) with process (restraint use). ${ }^{5}$

Beliefs about physical restraints have changed completely since the pioneering efforts of Lois Evans and Neville Strumpf. ${ }^{6}$ What was once considered good practice to ensure safety has been deemed an unnecessary restriction and a risk. ${ }^{7}$ Beliefs about the role of nurse staffing in improving quality have remained, although the evidence is inconsistent; there is a growing appreciation of the difficulty in establishing a causal relationship. Virtually all studies linking staffing and quality (including the one in this issue) are observational. ${ }^{8}$ Confounding is a persistent problem. ${ }^{9}$ There is a high likelihood that facilities that are concerned about quality (and have the resources to translate those concerns into action) will both minimize restraints and invest in staff.

The current study tries to get around this confounding by examining changing staffing patterns in the same facilities, an approach used by Needleman and colleagues. ${ }^{10}$ They matched quarterly data on restraint use with hospital nurse staffing levels. Restraint use was defined as any use. Nursing use was assessed in terms of both overall hours per patient day and the proportion of those hours that were performed by an RN. Patient mix was only crudely estimated; no diagnostic data were used. The authors looked at the correlation of skill mix (how many registered nurses [RNs] vs. licensed vocational nurses and nurses' aids) and staffing levels (overall nursing staff per patient day) but not the interaction between the two (i.e., does the proportion of RNs exert a different effect when the overall nursing staff is high or low?).

The findings seem sensitive to the method used. Skill mix was associated with less use of restraints, but when

Published online September 7, 2016

other factors were added to the model, neither skill mix nor staffing level was significantly associated with restraint use. The analysis compared staffing levels in quintiles around the mean. Presumably, the change in staffing from quarter to quarter should be enough to affect restraint use. But the variation was modest: total nursing hours per patient averaged 8.5, with an SD of 1.4. After excluding $25 \%$ of the sample, for units reporting no restraint use the level was $8.9 \pm 1.8$, whereas for those using restraints it was $8.5 \pm 1.7$, basically a $6 \%$ difference. Likewise, with skill mix, the units employing restraints at least some of the time (i.e., the study sample) had a level of $66.3 \pm 10.6$ percent RNs, whereas the unrestrained units (excluded from the study sample) had $66.4 \pm 10.6$, hardly anything to suggest a big difference. Using quintiles can create the appearance of variation were there may be little. Even here, the effect of overall staffing was seen for only one quintile and the effect of skill mix for only the lowest two. Presumably there is some threshold effect.

What do we glean from examining the relationship between restraints and nursing? Does it test an important hypothesis? Does it clarify the role of nursing? Is reducing restraint use a major priority? If so, would the best strategy be to increase nursing staff?

While having more and better staff seems like a nobrainer for improving quality, the effects of nurse staffing on the quality of hospital care have been widely debated to no clear bottom line. An Institute of Medicine (IOM) report concluded that "although it is difficult to prove causation, an emerging body of literature suggests that quality of care depends to a large degree on nurses". ${ }^{11}$

From a physician's perspective, if one wanted to look at the effects of nursing on quality, why not examine a more salient outcome, such as mortality or length of stay? General internists' interest in studies like this one will depend on their roles. For those working as hospitalists in an era of increasing accountability based on quality, their fate is closely linked to the hospital's performance, but physicians can influence the quality elements to different degrees. They have virtually no influence on structure, although they may advocate for more or better nursing. Process allows them to at least partially separate their actions from those of the other players, but they are still reliant on nurses. Indeed, physicians might order (or 
discontinue) restraints, but they are only bit players in the restraint show.

As accountability moves towards some variant of value purchasing, the big issue will be what constitutes quality. Given the tenuous links among Donabedian's triad, it makes the most sense to focus on outcomes, despite the problems of case mix adjustment. But focusing on outcomes means collective responsibility; everyone rises or falls on the performance of the whole care system.

For those practicing outside the hospital, information on restraint use might be modestly useful as at least part of the basis for referrals, but referring physicians have less and less influence on where patients are hospitalized. Attending physician admission privileges and plan restrictions are much stronger factors. If an internist did want to make a recommendation, how might she or he use this information? The use of restraints is an unlikely candidate as a key quality indicator for recommending a hospital. If you wanted a structural measure, why not go directly to nurse staffing? Is information on structure as salient as information on outcomes? Which outcomes count most? Would not risk-adjusted data on survival and improvement, or the rate of adverse events, provide a better basis for a recommendation?
Corresponding Author: Robert L. Kane, MD; University of Minnesota School of Public Health, Minneapolis, MN, USA (e-mail: kanex001@umn.edu).

\section{REFERENCES}

1. Donabedian A. Evaluating the quality of medical care. Milbank Mem Fund Q. 1966;XLIV(3):166-206.

2. Ayanian JZ, Markel H. Donabedian's Lasting Framework for Health Care Quality. N Engl J Med. 2016;375(3), 205-207.

3. McAuliffe WE. Studies of process-outcome correlations in medical care evaluations: a critique. Med Care. 1978;16(11):907-930.

4. Kane RL, Butler M, Ng W. Examining the quality of evidence to support the effectiveness of interventions: an analysis of systematic reviews. BMJ Open 2016. doi: 10.1136/bmjopen-2016-011051.

5. Staggs V, Olds DM, Cramer E, Shorr RI. Nursing skill mix, nurse staffing level, and physical restraint use in U.S. hospitals: a longitudinal study. J Gen Intern Med. 2016. doi:10.1007/s11606-016-3830-z.

6. Evans LK, Strumpf NE. Tying down the elderly. A review of the literature on physical restraint. J Am Geriatr Soc. 1989;37(1):65-74.

7. Miles SH, Irvine P. Deaths caused by physical restraints. Gerontologist. 1992;32(6):762-766.

8. Aiken LH, Sloane DM, Bruyneel L, et al. Nurse staffing and education and hospital mortality in nine European countries: a retrospective observational study. Lancet. 2014;383(9931):1824-1830.

9. Kane RL, Shamliyan TA, Mueller C, Duval S, Wilt TJ. The association of registered nurse staffing levels and patient outcomes: systematic review and meta-analysis. Med Care. 2007;45(12):1195-1204.

10. Needleman J, Buerhaus $\mathbf{P}$, Mattke $\mathbf{S}$, et al. Nurse-staffing levels and the quality of care in hospitals. N Engl J Med. 2002;346(22):1715-22.

11. Institute of Medicine. Future of Nursing: Leading Change, Advancing Health. Washington, DC: National Academies Press; 2011. 